\title{
Sensorless rotor position estimation of PMSM for low and high rotor speed
}

\author{
Ahmed G. Abo-Khalil \\ Electrical Engineering Department, Majmaah University, Almajmaah 11952, Kingdom of Saudi Arabia \\ Electrical Engineering Department, Assiut University, Assiut, 71515, Egypt \\ a.abokhalil@mu.edu.sa
}

Submitted: 09/02/2020

Revised: $12 / 04 / 2020$

Accepted: 22/04/2020

\begin{abstract}
In this paper, a sensorless permanent magnet synchronous motor (PMSM) drive was presented based on calculating the back EMF using the reference stator voltages, which are the output of the d-axis current controller, which includes information about the rotor position. Sensorless control estimates the position information necessary for vector control of the motor without using position sensor or encoder. This can provide effects such as increased system reliability and cost and volume reduction. The back EMFs are calculated in a new coordinate based on the estimated speed to minimize the rotor speed estimation error. The estimated rotor position and rotor speed may fail to track the real rotor position and real rotor speed in extremely low speed since the position error can be amplified from the current controller output voltage, and this may cause the instability problems of tracking controller. So, a compensator has been added to the detector to overcome this disadvantage. In order to verify the validity of the proposed sensorless control technique, an experiment was performed on the PMSM, and the results showed fast-dynamic response, low ripples in motor's currents, and good performance in tracking speed and power references.
\end{abstract}

Keywords: PMSM; Angle Detection; Position Estimation.

\section{INTRODUCTION}

PMSMs are widely used in military and civilian industries because of their advantages such as high efficiency, power density, robust structure, low inertia efficiency, and excellent control performance compared to DC motors and induction motors [1]. However, in order to operate the PMSM, the basic condition of knowing the relative position information of the rotor poles with respect to the stator's reference position must be satisfied. In general, a sensor for position detection, such as an encoder or resolver, is attached to a shaft of a rotor to measure and drive position information. In general, it can be pointed out that the cost of the position detection sensor is expensive, and there is a need for a separate space for installation. In particular, when used for driving a compressor, which is a core part of a home appliance such as a refrigerator or an air conditioner, it may be very difficult to install a position detecting sensor in the use environment.

If the PMSM is to be controlled without a position sensor, the motor rotor angle and speed control necessary information for torque control should be estimated from equations based on the basic model of the motor. In order to estimate the rotor position accurately, the mathematical model of the PMSM drive is obtained by using the voltage, flux, and speed equation. In conventional sensorless techniques, the focus is on the more accurate estimation of back EMF in obtaining information from voltage equations. 
As a technique of estimating speed and integrating it again to obtain information about the rotor angle, a method using a state estimator is most common [2].

So far, there have been several extensive researches applied to improve the rotor position sensorless control. The main approaches can be categorized into four major types:

(1) Magnetic flux detection technique by integration of voltage

The magnetic flux detection by the integration of voltage is obtained by integrating the terminal voltage of the motor using the electric equation of the motor to find the magnetic flux of the motor, and then estimating the rotor angle from it [3]-[7]. In the case of simple sensorless algorithms, the disadvantages of the algorithm itself are that it reacts sensitively to fluctuations in the motor's constants, in particular the stator resistance. In the algorithm using the integrator, it is very difficult to accurately integrate the motor terminal voltage generated by the PWM operation of the inverter, and inevitably an error occurs when performing the integration in the digital controller, and there is a slight voltage offset. If this exists, the problem that the integrator diverges occurs.

\section{(2) Technique by Back-EMF Estimation}

The method of estimating the counter electromotive force is a technique of estimating the counter electromotive force by compensating not only the voltage drop caused by the stator resistance in the terminal voltage of the motor, but also the voltage drop of the stator inductance [8]-[9]. The derivative is used to find the voltage drop of the inductance, and if the noise component is included in the actual current information and the voltage information, the reference model cannot be calculated accurately, which leads to a problem that the control becomes unstable.

(3) Techniques using state estimators

Commonly, the state estimator is a method of estimating speed by applying a state estimator to a mechanical equation and integrating it to obtain position information [10]-[11]. Accurate information is needed on all constants and variables related to the mechanical equation, for example, electrical torque, external load torque, and inertia of the motor. However, in general, the external load torque is extremely severely changed in some cases, so it is difficult to know the load torque exactly. As a result, accurate rotor angle estimation is not achieved, resulting in a synchronous outage phenomenon in which torque control is not achieved.

(4) Control method using Kalman filter

Many methods of estimating the information on the speed and position angle of a motor by applying a Kalman filter have been published [12]-[15]. In the case of the Kalman filter, the algorithm itself is extremely complex and generally requires to be applied to at least fourth-order nonlinear equations because the current, speed, and position angle are treated as state variables. The biggest problem when applying the Kalman filter algorithm is that it is very difficult to select the estimated gain because there is no way to evaluate the actual system noise fairly. In addition, considering that the experimental results are rarely given, the indirect differences between simulation and experimentation, such as system noise or computational delay, are a big obstacle to the practical implementation of these algorithms.

In this paper, a sensorless speed control method for a PMSM based on the back EMF the using rotor speed and position estimation is proposed by considering the estimated rotor speed and position in calculating the back EMF and its new coordinates. Experimental results show good current control results in the starting acceleration section, and good sensorless speed control performance can be verified at low speed of $5 \%$ of rated speed.

\section{SENSORLESS SPEED CONTROL}

Figure 1 shows the structure of a two-pole PMSM and its electrical equivalent model [16]. The PMSM consists of a stator with three-phase electric windings and a rotor with permanent magnets. In the stator, three-phase windings are electrically wound every 120 degrees, and a voltage transfer motor is applied externally through the windings. The 
relationship between the coordinate axes available in the sensorless position sensing method is shown in Fig. 2 [17]. The a, b, c coordinate system is represented by the a, b, c axes. The a, b, and c axes are based on the direction of the magnetic flux generated when current flows through the $a, b$, and $c$ phase windings, respectively.

In the case of the $\alpha \beta$ coordinate system, which is a Cartesian static coordinate axis, the alpha axis is the same axis as the (a)-axis, and the $\beta$ axis is electrically 90 degrees ahead of the $\alpha$ axis in the direction of rotation of the motor. The $\mathrm{a}, \mathrm{b}, \mathrm{c}$ coordinate system and the $\alpha \beta$ coordinate system are stationary coordinate systems. On the other hand, the synchronous coordinate system is a coordinate system that rotates at a synchronous speed according to the rotation of the rotor of the motor. In the case of the synchronous coordinate system, the d-axis is the same as the magnetic flux direction of the $\mathrm{N}$ pole of the permanent magnet, and the q-axis is electrically 90 degrees ahead of the d-axis in the direction of rotation of the motor. The direct and quadrature axes are the $\mathrm{d}$ - and q-axis directions that the controller estimates, which have errors as much as the actual dq and $\Delta \theta_{r}$. The current state equation of the controller of the PMSM to be controlled is expressed based on the synchronous dq coordinate system [18].

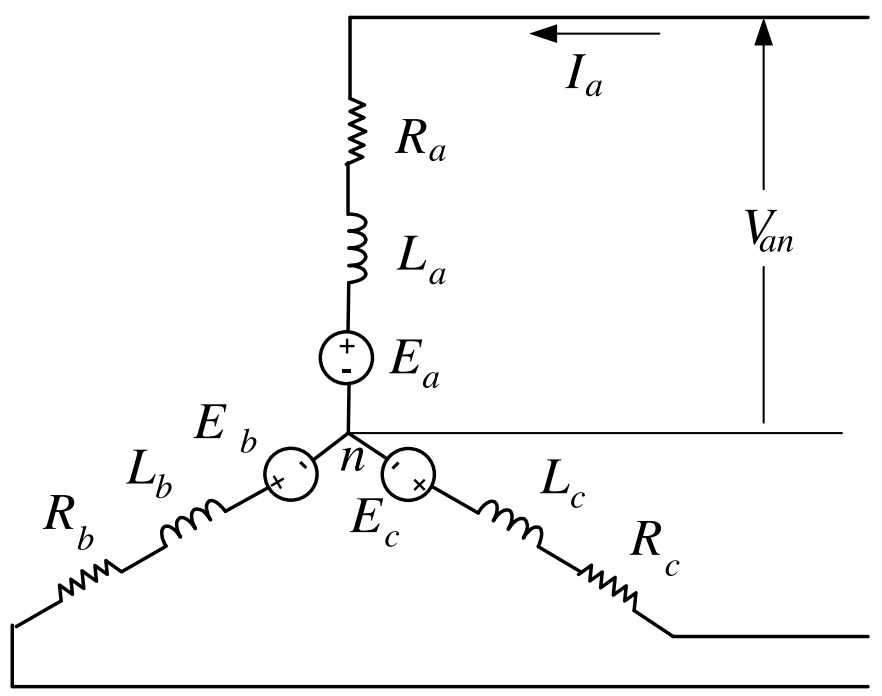

Figure 1. Equivalent circuit of permanent magnet synchronous motor.

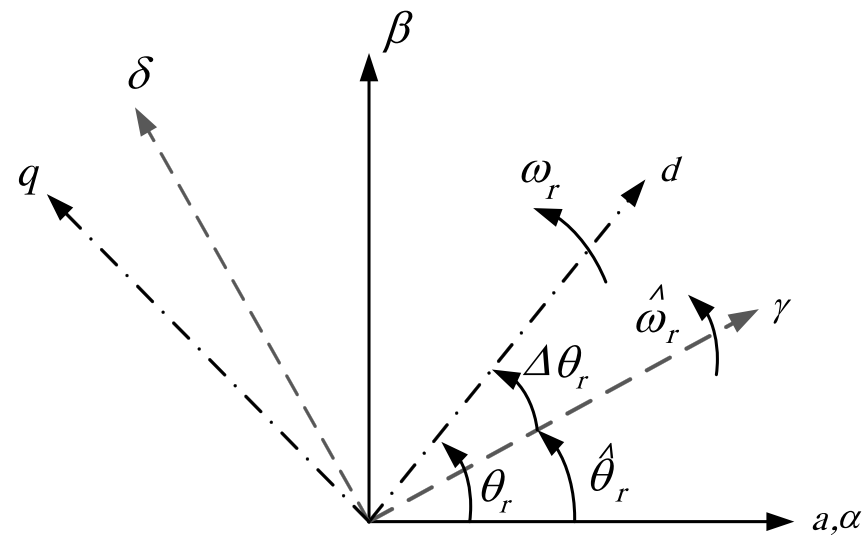

Figure 2. The new rotating reference $\gamma \delta$-axis. 


$$
\begin{aligned}
& v_{q}=R_{s} i_{q}+\omega_{r} \lambda_{d}+p \lambda_{q} \\
& v_{d}=R_{s} i_{d}-\omega_{r} \lambda_{q}+p \lambda_{d}
\end{aligned}
$$

In equations (1) and (2), $v_{d}$ and $v_{q}$ are stator voltages, $R_{S}$ is stator resistance, $i_{q}$ and $i_{d}$ are stator currents, $\omega_{r}$ is rotor speed, $\lambda_{q}$ and $\lambda_{d}$ are stator fluxes, and $p$ is a differential operator. The magnetic flux is

$$
\begin{aligned}
& \lambda_{q}=L_{q} i_{q} \\
& \lambda_{d}=L_{d} i_{d}+\lambda_{m}
\end{aligned}
$$

In Eqs. (3) and (4), $L_{q}$ and $L_{d}$ are magnetic inductances, and $\lambda_{m}$ is the linkage flux of the permanent magnet. In summary, the following equation can be obtained.

$$
\begin{aligned}
& p i_{q}=\frac{1}{L_{q}}\left(v_{q}-r_{s} i_{q}-\omega_{r} L_{d} i_{d}-\omega_{r} \lambda_{m}\right) \\
& p i_{d}=\frac{1}{L_{d}}\left(v_{d}-r_{s} i_{d}+\omega_{r} L_{q} i_{q}\right)
\end{aligned}
$$

Figure 2 shows the dq coordinate system, where the dq axis represents the actual rotor position [19]. Since the estimated rotor position is not exactly the same as the actual position, the $\gamma \delta$-axis represents the estimated rotor position and has a shift of $\Delta \theta_{r}$ from the dq-axis. Assuming that the rotor position estimation error $\Delta \theta_{r}$ and the speed estimation error $\Delta \omega_{r}$ are small, the $\gamma \delta$-axis voltage equation based on the estimated rotor position can be expressed as equations (7) and (8).

$$
\begin{aligned}
& {\left[\begin{array}{l}
v_{\gamma} \\
v_{\delta}
\end{array}\right]=\left[\begin{array}{cc}
r_{s}+L_{d} p & -\omega_{r} L_{q} \\
\omega_{r} L_{q} & r_{s}+L_{d} p
\end{array}\right]\left[\begin{array}{l}
i_{\gamma} \\
i_{\delta}
\end{array}\right]+\left[\begin{array}{l}
e_{\gamma} \\
e_{\delta}
\end{array}\right]} \\
& {\left[\begin{array}{l}
e_{\gamma} \\
e_{\delta}
\end{array}\right]=\omega_{r} \lambda_{m}\left[\begin{array}{c}
-\sin \Delta \theta_{r} \\
\cos \Delta \theta_{r}
\end{array}\right]}
\end{aligned}
$$

From equation (7), the positional error between the actual rotor position and the estimated rotor position can be derived, and the estimated position error can be represented by equation (9).

$$
\Delta \theta_{r}=\tan ^{-1}\left(\frac{-e_{\gamma}}{e_{\delta}}\right)
$$

The $\gamma \delta$-axis back-EMF in (9) can be obtained from Eqs. (7), and it can be expressed by Eq. 10:

$$
\left[\begin{array}{l}
e_{\gamma} \\
e_{\delta}
\end{array}\right]=\left[\begin{array}{l}
v_{\gamma}+\widehat{\omega}_{r} L_{q} i_{\delta}-\left(r_{s}+L_{d} s\right) i_{\gamma} \\
v_{\delta}-\widehat{\omega}_{r} L_{q} i_{\gamma}-\left(r_{s}+L_{d} s\right) i_{\delta}
\end{array}\right]
$$

where $\widehat{\omega}_{r}$ is the estimated rotor speed.

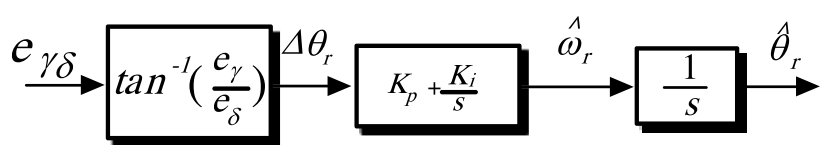

Figure 3. Rotor position and rotor speed estimator. 
Equation (9) is used as the input of the proportional integral controller, and the output of the proportional integral controller is set to the estimated rotor angular velocity.

The PI controller gains can be expressed as follows:

$$
\begin{aligned}
& K_{P}=\omega_{g} \sqrt{\frac{\left(\tan \varphi_{m}\right)^{2}}{1+\left(\tan \varphi_{m}\right)^{2}}} \\
& K_{i}=\omega_{g}^{2} \sqrt{\frac{1}{1+\left(\tan \varphi_{m}\right)^{2}}}
\end{aligned}
$$

where $K_{p}, K_{i}, \varphi_{m}$, and $\omega_{g}$ are the proportional gain, integral gain, phase margin, and the bandwidth, respectively.

Figure 3 shows a block diagram of a rotor position and speed estimator. The rotor position error is given by equations (9) and (10), and the rotor position error is compensated for rotor estimated speed by PI control. The estimated rotor position is obtained by integrating the estimated rotor speed. In general, in Eq. (10), the $\gamma \delta$-axis backEMF is estimated using the output of the current controller.

In very low rotating speed, the estimated speed is very low, and it may make the estimated rotor position error $\theta_{\text {err }}$ become very large and the input of the position estimation PI controller become very large. This destabilizes the operation of the PI controller, which leads to poor start-up characteristics and, in some cases, causes start-up failures. Therefore, the speed estimation method shown in Figure 3 can be accurate in areas where the speed has increased by more than a certain degree. In order to avoid such a problem, a constant frequency pattern uses a method of starting the motor with open loop control at a low speed, and then switching to vector control when the speed increases over a certain speed. When this method is applied, it is difficult to adjust the acceleration/deceleration time because it needs to accelerate slowly in order to synchronize with the rotating magnetic field during start-up, and the current or voltage and frequency ratio of the open loop control must also be selected by trial and error. This is a long and probable mechanical and electrical problem during the tuning process.

To compensate this drawback at low speed, a simple dynamic compensator is added to improve the dynamic characteristics at low speed as shown in Fig. 4. By applying the fast compensator to the sensorless controller, it can be seen that the bandwidth at the low speed is increased. However, increasing the bandwidth through the compensator can lead to unstable operation due to inverter nonlinearity, which must be retuned through experimentation. The proposed method has the advantage that the motor constant is less dependent, and the algorithm is extremely simple compared to the existing methods.

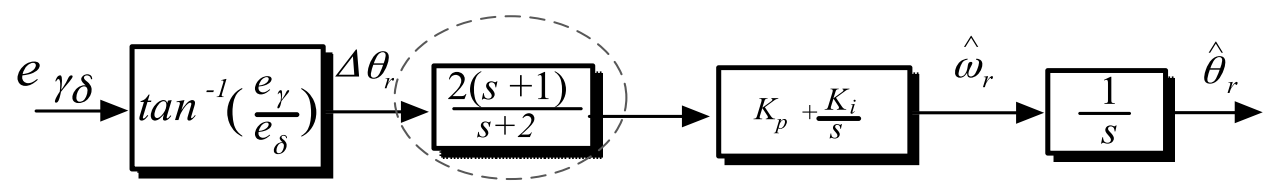

Figure 4. Block diagram of the proposed sensorless control with lead compensator. 


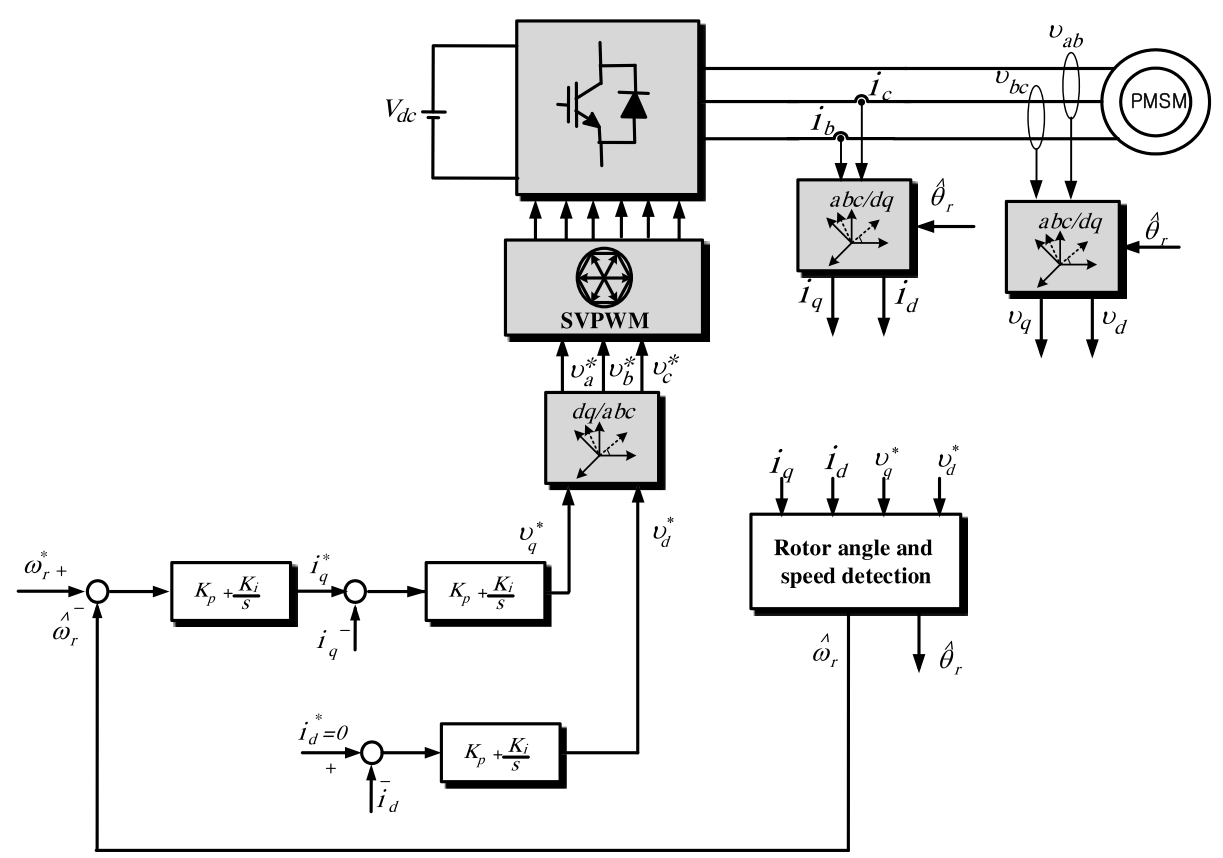

Figure 5. Block diagram overall control structure of constant frequency pattern method.

A complete block diagram of the proposed sensorless control of PMSM drive is shown in Fig. 5. The speed controller basically generates a current command so that the actual motor speed follows the speed command given from the outside. Therefore, the speed controller can fulfill its function only when the basic assumption that the torque coinciding with the current command is accurately output from the electric motor is established. This current command is fed to the current controller and used as the reference current of the current controller. At this time, the current controller operates fast enough so that the same current as the reference value is applied to the motor.

\section{EXPERIMENTAL RESULTS}

Figure 6 shows the complete control system built for the experiment to control permanent magnet synchronous motor. Basic configuration consists of $2.7[\mathrm{~kW}]$ PMSM, $3[\mathrm{~kW}]$ DC generator as a load used as wind simulator, inverter to supply electric power, and controller. The switching frequency of the PWM inverter was $10 \mathrm{kHz}$, and the processor used was TMS320VC33-120MHz. The specifications of the PMSM are shown in Table 1 in the appendix.

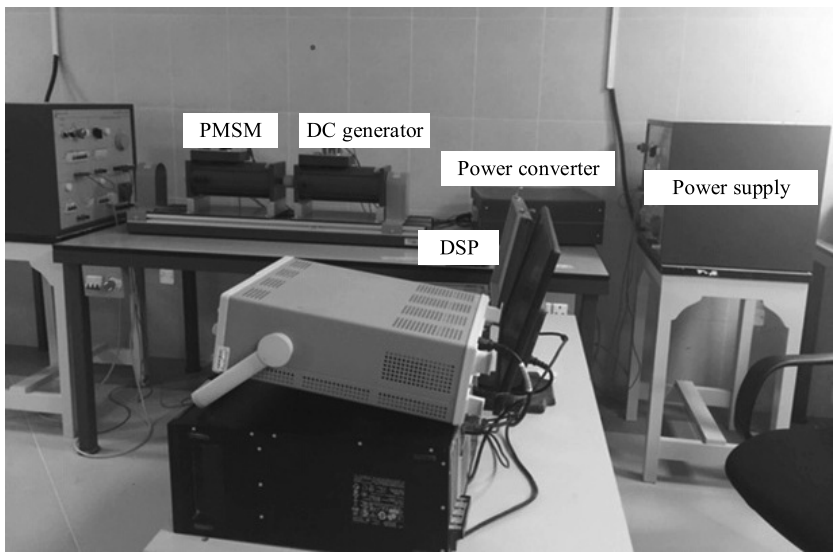

Figure 6. PMSM experimental setup. 
Figure 7 shows the estimated speed, measured speed, and rotor position when the speed command of 400 [rpm] is given in steps. From the above, the estimated speed and measured speed show good speed response characteristics and estimated characteristics in the transient and steady state with respect to the step speed command.

Figure 8 shows the estimated speed and actual speed, estimated rotor position, and actual rotor position for the speed command of 400 [rpm]. In this figure, it can be seen that, in the transient state at the initial low speed, the dynamic characteristics are lowered because the bandwidth of the rotor position estimation PI controller is low. In the same principle, the estimated rotor position is also initially slow due to low bandwidth, but after a certain speed, the estimated bandwidth is also improved.

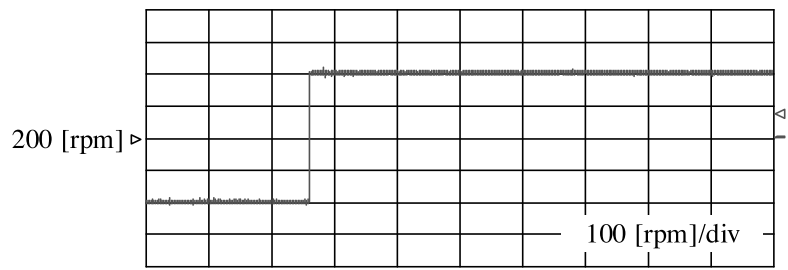

(a)

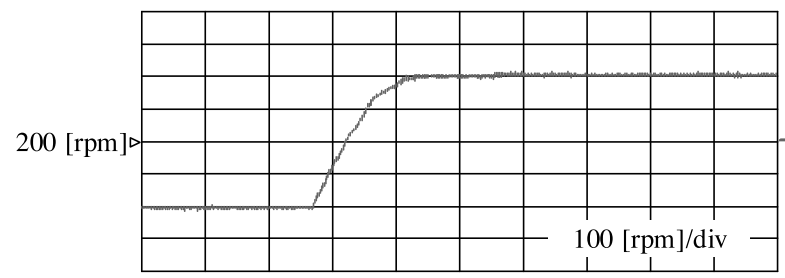

(b)

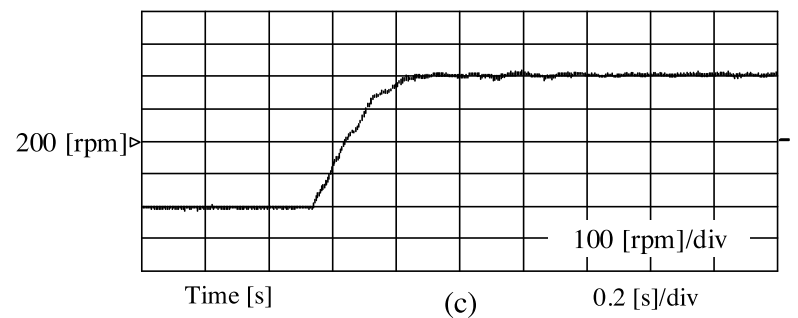

Figure 7. Estimated and measured speed/position with a step 400rpm command change.

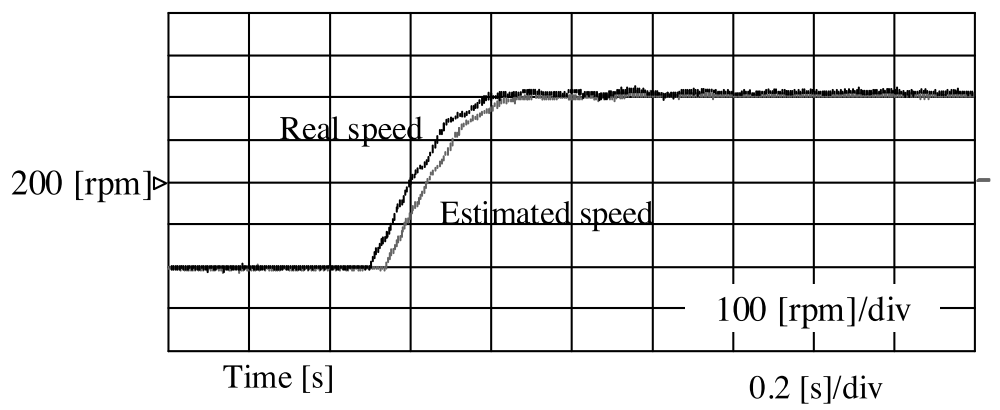

Figure 8. Estimated speed/position with a step 400rpm command change.

Figure 9 shows rotor position estimation characteristics at steady state for the speed command of 400 [rpm]. As can be seen from the figure, the rotor position error in the low speed region of 400 [rpm] is almost zero, which shows good position estimation characteristics. 
Figure 10 shows the estimated and measured rotor speed when the speed command is changed to 500-600-500 [rpm]. As can be seen from the figure, even when the speed command is changed to 500-600-500 [rpm] in steps, it shows stable response characteristics and estimated characteristics.

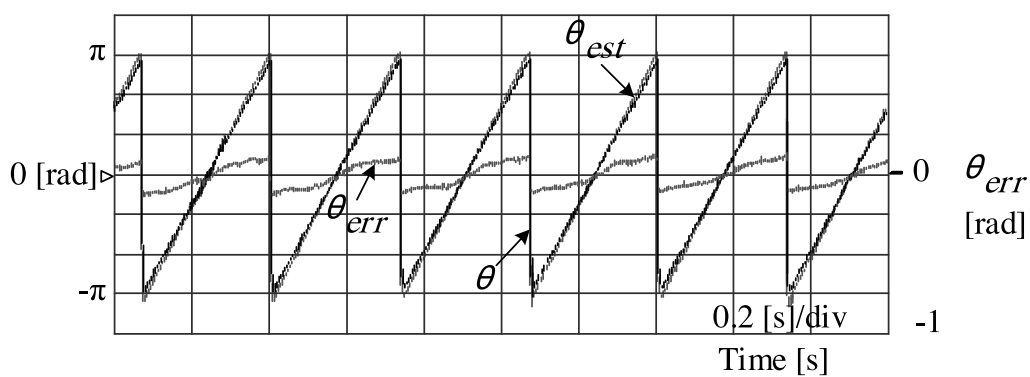

Figure 9. Responses of position estimation with $400[\mathrm{rpm}]$ speed command (steady state).

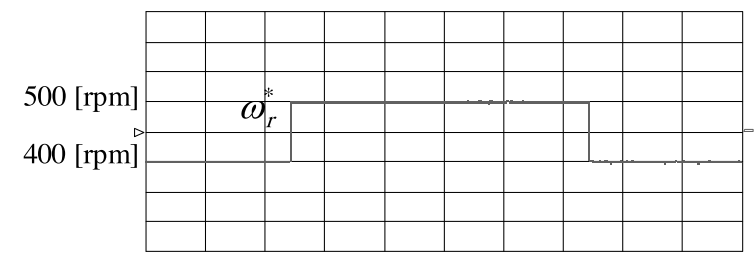

(a)

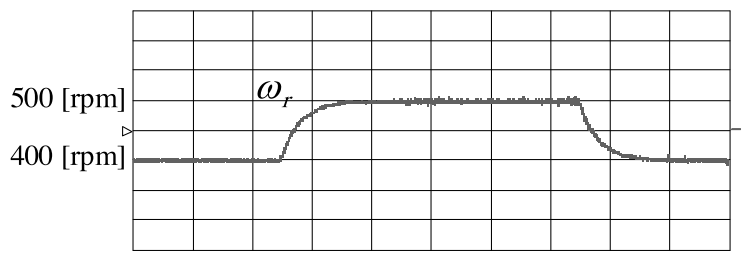

(b)

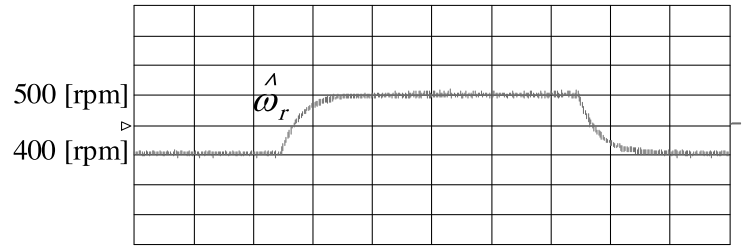

(c)

$0.5[\mathrm{~s}] / \mathrm{div}$

Figure 10. Responses of 400-500-400 [rpm] step speed command.

Figure 11 shows the performance of the speed controller at $800 \mathrm{rpm}$ speed command. It is noticed that the speed is maintained at $800 \mathrm{rpm}$, and the q-axis current is well controlled with low harmonic content. 


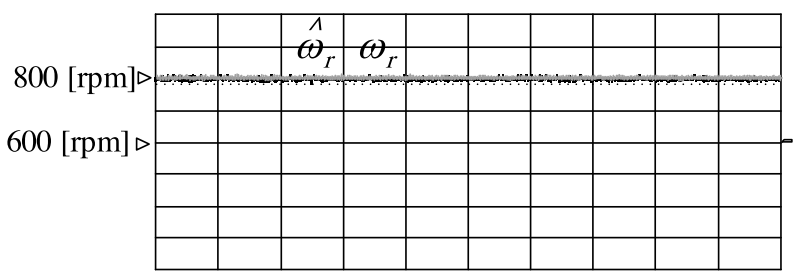

(a)

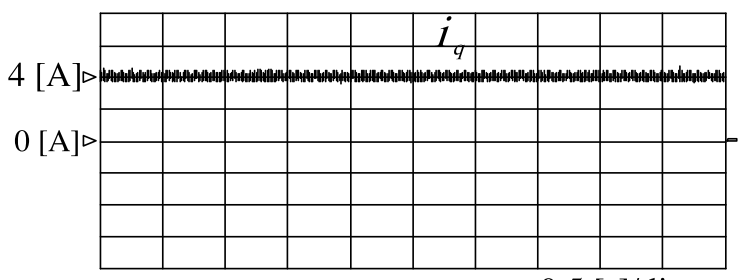

(b)

$0.5[\mathrm{~s}] / \mathrm{div}$

Figure 11. Steady-state responses of $800[\mathrm{r} / \mathrm{min}]$ speed command with full load test.

\section{CONCLUSION}

In this paper, a sensorless method that can be applied to high and low speed operation of PMSM such as turbo compressors and flywheels is proposed. Considering the error between the actual rotor position and the estimated position, the back emf is determined based on the estimated speed and position. A new rotating reference frame, namely, $\gamma \delta$-axis, is presented. The two components of EMF are then analyzed in the new coordinates and used to detect and control the motor speed. A lead error compensator is added to the detector to reduce the error in the starting and low speed conditions. By performing and experiments, we verified the superiority and feasibility of all the proposed algorithms and also showed that the sensorless PMSM controller for high performance control can be put into practical use.

\section{ACKNOWLEDGMENT}

The author would like to thank Deanship of Scientific Research at Majmaah University for supporting this work under Project Number No. (RG. 2019-19)

\section{REFERENCES}

Abo-Khalil, A.G. Berrouche, Y. Barhoumi, E.M. Baseer, A.M. Praveen, R.P. \& Awan, A.B. 2016. A low-cost PMSG topology and control strategy for small-scale wind power generation systems. International Journal of Engineering Sciences \& Research Technology, IJESRT, 585-592.

Baseer, A.M. Abo-Khalil, A.G. \& Agora, S. 2015. Positioning and adjusting the frequencies of the rotor in permanent magnet synchronous machine to achieve high performance" International Journal of Applied Engineering Research, 10(59): $379-386$.

Chan, T.F. Wang, W. Borsje, P. Wong, Y.K. \& Ho, S.L. 2008. Sensorless permanent-magnet synchronous motor drive using a reduced-order rotor flux observer. IET Electric Power Applications, 2: 88-98.

Fernandes, E.M. Oliveira, A.C. Vitorino, M.A. Dos Santos, E.C. \& Santos, W. R.N. 2014. Speed Sensorless PMSM Motor Drive System Based on Four Switch Three-Phase Converter. In Proceedings of the 40th Annual Conference of the IEEE Industrial Electronics Society, Dallas, TX, USA.

Flieh, H. Slininger, T. Lorenz, R.D. \& Totoki, E. 2018. Self-Sensing via Flux Injection with Servo Dynamics including a Smooth Transition to Back-EMF Tracking. In Proceedings of the 2018 IEEE Energy Conversion Congress and Exposition (ECCE), Portland, OR, USA: 1762-1769. 
Janiszewski, D. 2012. Unscented Kalman Filter for sensorless PMSM drive with output filter fed by PWM converter. In Proceedings of the IECON 2012 - 38th Annual Conf. IEEE Industrial Electronics Society, Monteral, QC, Canada: 4660-4665.

Kivanc, O.C. \& Ozturk, S.B. 2015. MATLAB Function Based Approach to FOC of PMSM Drive. In Proceedings of the IEEE European Modelling Symposium, Madrid, Spain.

Kwon, Y.C. Sul, S.K. Baloch, N.A. Murakami, S. \& Morimoto S. 2016. Improved design of IPMSM for sensorless drive with absolute rotor position estimation capability. IEEE Transaction of Industrial Applications, 52(2): 1441-1451.

Ma, Z. \& Zhang, X. 2018. FPGA Implementation of Sensorless Sliding Mode Observer With a Novel Rotation Direction Detection for PMSM Drives. IEEE Access, 6: 55528-55536.

Moujahed, M. Ben Azza, H. Jemli., M. \& Boussak, M. 2013. Sensor-less direct torque control of permanent magnet synchronous motor drive using Extended Kalman filter," Electrical Engineering and Software Applications (ICEESA): 1-6.

Park, N.C. \& Kim, S.H. 2014. Simple sensorless algorithm for interior permanent magnet synchronous motors based on highfrequency voltage injection method. IET Electric Power Applications, 8(2): 68-75.

Shi, Y. Sun, K. Huang, L. \& Li, Y. 2011. On-line identification of permanent magnet flux based on extended Kalman filter for IPMSM drive with position sensorless control. IEEE Transaction of Industrial Electronics, 59(11): 4169-78.

Song, X. Fang, J. Han, B. \& Zheng, S. 2016. Adaptive Compensation Method for High-Speed Surface PMSM Sensorless Drives of EMF-Based Position Estimation Error. IEEE Trans. Power Electron, 31: 1438-49.

Wang, Z. Lu, Q. Ye, Y. Lu, K. \& Fang, Y. 2012. Investigation of PMSM Back-EMF using Sensorless Control with Parameter Variations and Measurement Errors. Przeglad Elektrotechniczny, 88: 182-186.

Wang, Y. Xu Y. \& Zou, J. 2019. Sliding mode sensorless control of PMSM with inverter nonlinearity compensation. IEEE Trans. Power Electronics, 34(10): 1450-1460.

Wisniewski, J. \& Koczara, W. 2008. The sensorless rotor position identification and low speed operation of the axial flux permanent magnet motor controlled by the novel PIPCRM method. In Proceedings of the 2008 IEEE Power Electronics Specialists Conference, Rhodes, Greece: 1502-1507.

Xu, D. Wang, G. Zhang, G. \& Yu, Y. 2018. A review of sensorless control methods for AC motor drives. CES Trans. Elect. Mach. Syst. 2: 104-115.

Xu, W. Jiang Y. Mu, C. \& Blaabjerg, F. 2019. Improved nonlinear flux observer-based second-order SOIFO for PMSM sensorless control. IEEE Trans. Power Electronics, 34: 565-579.

\section{APPENDICES}

The specification of the PMSM used for test is listed in Table 1.

Table 1. Parameters of the PM synchronous machine.

\begin{tabular}{|c|c|}
\hline Parameters & Value \\
\hline Rated Power & $2.7[\mathrm{~kW}]$ \\
\hline Rated speed & $1200[\mathrm{rpm}]$ \\
\hline Number of poles & 6 \\
\hline Rated current & $9.5[\mathrm{~A}]$ \\
\hline Stator resistance & $0.5[\Omega]$ \\
\hline d-axis inductance & $3[\mathrm{mH}]$ \\
\hline q-axis inductance & $7[\mathrm{mH}]$ \\
\hline Flux Linkage & $0.175[\mathrm{~Wb}]$ \\
\hline Moment of inertia & $1.8 \times 10^{-3}\left[\mathrm{~kg} \cdot \mathrm{m}^{2}\right]$ \\
\hline
\end{tabular}

